\title{
In vitro Antifungal Activity of Cucumis melo on Candida albicans
}

\author{
Issa Gholampour-Azizi ${ }^{1}$; Samaneh Rouhi ${ }^{2}$; Fahimeh Yahyayi ${ }^{3, *}$ \\ ${ }^{1}$ Department of Mycology, Babol Branch, Islamic Azad University, Babol, IR Iran \\ 2Department of Mycology, Babol Branch, Islamic Azad University, Babol, IR Iran \\ ${ }_{3}^{2}$ Department of Microbiology, Cellular and Molecular Research Center, Kurdistan Univer
Department of Botany, Qaemshahr Branch, Islamic Azad University, Qaemshahr, IR Iran \\ *Corresponding author: Fahimeh Yahyayi, Department of Botany, Qaemshahr Branch, Islamic Azad University, Qaemshahr, IR Iran. E-mail: microbiol_sci@yahoo.com
}

Received: February 3, 2014; Accepted: March 26, 2014

\begin{abstract}
Background: With respect to the emergence of susceptibility of some fungi to antifungal agents, making use of medicinal plants is progressing.

Objectives: The aim of this study was to verify the anti-fungal characteristics of mature and immature Cucumis melo fruit on Candida albicans.

Materials and Methods: In this descriptive study, antifungal activity of aqueous, ethnolic and methanolic extracts of C. melo fruits were tested on C. albicans; also results were obtained by disc and well diffusion methods.

Results: Minimum inhibitory concentration (MIC) and minimum fungicidal concentration (MFC) of mature C. melo fruit methanolic extract were $25 \times 10^{3}$ and $5 \times 10^{4} \mu \mathrm{g} / \mathrm{mL}$, respectively. MIC and MFC of immature fruit methanolic extract was $25 \times 10^{3}$. For mature fruit ethanolic extract, MIC and MFC was $25 \times 10^{3} \mu \mathrm{g} / \mathrm{mL}$ and for immature $C$. melo fruit ethanolic extract MIC was $25 \times 10^{3}$ and MFC was $5 \times 10^{4}$ $\mu \mathrm{g} / \mathrm{mL}$. Gas chromatography/mass spectrometry (GC/MS) results showed that hexadecanoic acid was present in all of the extracts. The maximum size of inhibition zone for mature and immature methanolic extact in the disc method was $12 \mathrm{~mm}$ and in well method were 15 and $17 \mathrm{~mm}$, respectively. In the disc method, for mature and immature ethanolic extracts maximum size of inhibition zones were 35 and $36 \mathrm{~mm}$ and in the well method, maximum size of inhibition zones for mature and immature ethanolic extracts were $28 \mathrm{and} 15 \mathrm{~mm}$, respectively.

Conclusions: These results indicated that C. melo extracts contain compounds with therapeutic potential and anti-fungal characteristics against C. albicans.
\end{abstract}

Keywords: Antifungal activity; Cucumis melo; Candida albicans; In vitro

\section{Background}

Opportunistic pathogens are accounted for a substantial morbidity rate and can result in hospitalization and expensive therapies, and they also reduce the survival rate of people with HIV infection. For immune-compromised patients, Candida albicans is an important opportunistic fungal pathogen and the major cause of oropharyngeal candidiasiss [1]. Nosocomial candidiasis is a worldwide problem. Candida is the fourth common nosocomial infections in USA [2,3]. It causes urinary tract (UT) and blood infection in patients that admitted to the hospital $[4,5]$.

In (HIV)-infected patients, oropharyngeal colonization by Candida causes subsequent development of yeast infections; however, long-term therapy might lead to resistance development [6]. According to the literature, the investigation for natural products to be used against Candida species increased significantly in the last 10 years examining approximately 258 plant species from 94 families $[2,7]$. Wild melon (Cucumis melo L.), belongs to the cucurbitaceae family, it is an annual plant, herbaceous, prostrates, creeping and its fruit is as large as $2-40 \times 8$ $-24 \mathrm{~mm}$, it is ellipsoid and yellow and dark green veined with bitter pulps [8].
In various cucurbitaceous plants, a bitter material named cucurbitacine exists in different types (A, B, C, D, E, F, G, H, I, J, K, L). Cucurbitacine glycosides are tetra cycle three terpenic and have anti-tumor effects. This plant has medicinal use on common medicine. The plant's fruit is used as vomitive but in little amounts consumed with honey is tonic for stomach. Paste of its crushed grain along with Cynodon dactylon juice is used for curing and removing herpes grains and boils [9].

The anti-fungal characteristics of some medicinal plants on different species of fungi are already determined. Nadimi et al. reported that aqueous and ethanolic extracts of Teucrium polium had effect on C. albicans and Malassezia [9]. Marzouk et al. showed that Citrullus colocynthis had anti-bacterial and anti-candidal properties [10].

Kumar and Kamaraj reported that ethanolic fruit extract of Cucumis anguria have higher activity against both bacteria and fungi, also methanol chloroform and ethyl acetate extracts have moderate inhibitory effects on bacteria and fungi [11]. Because of the anti-fungus effects of some plants from Cucurbitaceae family, we set out to find any anti-fungal characteristics of both mature and imma-

Copyright (C) 2015, Zahedan University of Medical Sciences. This is an open-access article distributed under the terms of the Creative Commons Attribution-NonCommercial 4.0 International License (http://creativecommons.org/licenses/by-nc/4.0/) which permits copy and redistribute the material just in noncommercial usages, provided the original work is properly cited. 
ture wild melon on C. albicans by disc, well diffusion, MIC (minimum inhibitory concentration) and MFC (minimum fungicidal concentration) determination.

\section{Objectives}

The aim of this study was to verify the anti-fungal characteristics of mature and immature C. melo fruit on C. albicans.

\section{Materials and Methods}

In this descriptive study, mature and immature fresh fruits of C. melo were collected from different farms located in Mazandaran province, Babol city, North of Iran, Mid-September 2012. After collecting fruits, the skin of fruits was peeled; they were washed, then both mature and immature fruits were dried under shade at room temperature $\left(27^{\circ} \mathrm{C}\right)$ for 1 month. After that dried, samples were grinded into fine powder [12,13].

\subsection{Fungal Cultures}

C. albicans isolate (ATCC 10231) for this study was provided by Pasteur Institute of Iran. C. albicans isolate was located in lyophilized vials. It was cultured as linear culture on Sabouraud Dextrose Agar (SDA) medium (Merck, Germany) plates. Then they were incubated at $35^{\circ} \mathrm{C}$ for 2 days. Re-confirmation of $C$. albicans was performed at the laboratory of Mycology Department, Faculty of Veterinary Medicine, Islamic Azad University, Babol Branch, Babol, Iran. Laboratory diagnosis such as periodic acidSchiff(PAS) staining, growth in SDA containing antibiotic (chloramphenicol and gentamicin to prevent the growth of bacteria), sugar fermentation and assimilation tests with Rap ID yeast kit (BioTeke, China), microscopic observation of long germ tubes, hyphae, blastoconidia and chlamydoconidia production was performed before the start of examinations [14-16].

\subsection{Suspension Preparation}

Fresh cultivated $C$. albicans colonies were suspended in $5 \mathrm{~mL}$ of $0.85 \%$ normal saline. Suspension was mixed for 15 seconds with a vortex. Then its concentration was adjusted to $1.5 \times 108 \mathrm{CFU} / \mathrm{mL}$ based on a standard $0.5 \mathrm{Mc}$ Farland $[2,17,18]$.

Preparation of aqueous extract: Percolation method was performed to prepare the fruits' extracts. Twenty-five grams of dried samples powder was mixed with $250 \mathrm{~mL}$ of water, and it was shaken in Erlenmeyer flask continuously for 3 minutes, then it was stored at room temperature $\left(22^{\circ} \mathrm{C}\right.$ for 24 hours $)$. In the next step the extract was filtered through Whatman No. 1 (9 mm diameter) filter paper (Behan, Iran); then the filtered extract was entered in Rotary for removing solvent. Then aqueous extract was dried in incubator at $40^{\circ} \mathrm{C}$. In the end, $1 \mathrm{~g}$ of dried extract was mixed with $5 \mathrm{~mL}$ of $5 \%$ dimethyl sulphoxide (DMSO). Then it was filtered through a millipore syringe filters with $0.22 \mu$ diameter $[12,17]$.

\subsection{Preparation of Ethanolic and Methanolic Ex- tract}

For preparation of ethanolic and methanolic extracts, $20 \mathrm{~g}$ of mature and immature dried fruit of C. melo was mixed with $100 \mathrm{~mL}$ of $80 \%$ ethanol and $100 \mathrm{~mL}$ of $80 \%$ methanol, respectively. Then $100 \mathrm{~mL}$ of D-ethyl ether and N-hexane were added to them and then the mixture was wrapped in aluminum foil and stored at room temperature $\left(22^{\circ} \mathrm{C}\right.$ for 24 hours). Then extract was filtered through Whatman No. 1 (9 $\mathrm{mm}$ diameter) filter paper. Filtered extract was entered in Rotary for removing alcoholic solvent. Extract was dried in incubator at $40^{\circ} \mathrm{C}$. Then $1 \mathrm{~g}$ of alcoholic dried extract was mixed with $5 \mathrm{~mL}$ of 5\% DMSO and it was filtered through a millipore syringe filters with $0.22 \mu$ diameter $[2,12,17]$.

Determining antifungal activities using the disc diffusion method: The agar disc diffusion method was employed to determine antifungal activity in this study. Suspension of C. albicans $(1.5 \times 108 \mathrm{CFU} / \mathrm{mL})$ through the lawn culture was planted on SDA plates by swap. Sterile blank discs with $6 \mathrm{~mm}$ diameter (Pattan Teb, Iran) were impregnated with $40 \mu \mathrm{L}, 50 \mu \mathrm{L}, 60 \mu \mathrm{L}$ and $70 \mu \mathrm{L}$ dilutions of plant extract, after drying, standard discs were put on agar media with sterile forceps that were inoculated by C. albicans. Positive controls were amphotericin B (10 $\mu \mathrm{g})$, ketoconazole $(15 \mu \mathrm{g})$, nystatin $(50 \mu \mathrm{g})$ discs (Master Group Ltd, England) and negative control was a disc containing DMSO. Plates were incubated at $35^{\circ} \mathrm{C}$ for 48 hours. Principles that were used in this step were performed according to NCCLS standard (Table 1) [17, 19].

\subsection{Determining Antifungal Activities Using the Well Diffusion Method}

SDA medium was inoculated with C. albicans suspension by swap. Then $5 \mathrm{~mm}$ wells were caved in it by Pasteur

\begin{tabular}{lccc}
\hline Table 1. Susceptibility of C. Albicans to Antifungal Drugs According to NCCLS Disk Diffusion Method (mm) & \\
\hline Drug $\mu$ g/mL & Sensitive & Dose-Dependent & Resistance \\
\hline Amphotericin-B & $\geq 15 \mathrm{~mm}$ & $10-14 \mathrm{~mm}$ & $\leq 10 \mathrm{~mm}$ \\
Ketoconazole & $\geq 28 \mathrm{~mm}$ & $21-27 \mathrm{~mm}$ & $\leq 20 \mathrm{~mm}$ \\
Nystatin & $\geq 15 \mathrm{~mm}$ & $10-14 \mathrm{~mm}$ & Without inhibition zone \\
\hline
\end{tabular}


pipette. Number of wells was 5 on plates, being $25 \mathrm{~mm}$ apart and having a $15 \mathrm{~mm}$ space from the plate wall. Bottom of wells was closed with medium, aseptically. Then $30 \mu \mathrm{L}$ of $80 \mu \mathrm{L}, 90 \mu \mathrm{L}, 100 \mu \mathrm{L}$ and $110 \mu \mathrm{L}$ of each extract were added to wells. A cavity containing 100 U/Disc amphotericin B (Sigma, USA) that was dissolved in 5\% DMSO was considered as positive control and a cavity containing DMSO was considered as negative control. Positive and negative controls indicating the validity of the test and eliminating positives and negatives false. These plates were incubated at $35^{\circ} \mathrm{C}$ for 48 hours. After incubation, inhibition zone was observed and it was determined in millimeters. Each experiment for disc and well method was repeated 3 times and the mean of results was recorded $[2,20]$.

\subsection{MIC Determination}

MIC determination was performed using the serial dilutions method. At first, suspension of C. albicans according to standard 0.5 McFarland was provided in sabouraud dextrose broth (SDB) (Merck, Germany). Eleven tubes were considered. One millimeter of SDB was added to them. In the next step $1 \mathrm{~mL}$ of extract was added to tubes according to serial dilutions procedure. Also 20 $\mu \mathrm{L}$ of $C$. albicans suspension was added to tubes. Then they were incubated in $35^{\circ} \mathrm{C}$ for 24 hours. Tube number 11 was considered as the control tube $(1 \mathrm{~mL} \mathrm{SDB}+20 \mu \mathrm{L} \mathrm{C}$. albicans suspension). After incubation, with observation of turbidity or lack of turbidity in tubes, level of MIC was determined.

Determination of the MFC in prepared extracts: To determine the MFC, tubes without darkness were taken and then were cultured in SDA by sowap. Plates were incubated at $35^{\circ} \mathrm{C}$ for 48 hours. MFC was considered as colonyforming unit (CFU) that is an estimate of viable or fungal numbers. Minimum concentration that inhibited the growth of C. albicans was considered as MFC [13, 21].

\subsection{Gas Chromatography-Mass Spectrometry (GC- MS) Procedure}

In this research, for determination of constituent compounds of extracts, at first aqueous and alcoholic extracts were prepared using mature and immature wild melon. Components of different extracts of $C$. melo were detected and separated using the GC/MS chromatograph system (HP 6890, model) with HP-5MS column $(240 \mathrm{~m} \times$ $0.25 \mathrm{~mm}$ ). One microliter of extracts was injected into the $\mathrm{GC} / \mathrm{MS}$ system. Injector was programmed as follows: $6^{\circ} \mathrm{C}$ at 1 minute, then gradually increased to $240^{\circ} \mathrm{C}$. Helium was at a flow rate of $1 \mathrm{~mL} / \mathrm{mn}$. Injection temperature was $250^{\circ} \mathrm{C}$. Compounds of each extract were identified after analyzing the chromatogram [22].

\subsection{Statistical Analysis}

In order to analyze the information, descriptive and inferential methods were utilized. Student's $t$-test was used in our study for analysis of information. All of our analysis was done by SPSS-16. P-Values $<0.05$ were considered statistically significant.

\section{Results}

C. albicans showed no sensitivity to the aqueous extract of mature and immature wild melon in disc and well diffusion methods and C. albicans colonies were observed in all parts of plate.

Alcoholic extracts of mature and immature fruit of C. melo in the disc diffusion method showed less effect comparing to well diffusion method. Also ethanolic extract of immature wild melon in disc method showed a better effect on C. albicans than well diffusion method.

In this study, by increasing the amount of alcoholic extract on disc and well diffusion methods, inhibition zone around the disc and wells was increased. Various sizes of inhibition zones were measured by a ruler in millimeters. The maximum size of inhibition zone for mature and immature methanolic extact in the disc method was $12 \mathrm{~mm}$ (70 $\mu \mathrm{L}$, resistant) and in well method was 15 and 17 $\mathrm{mm}(110 \mu \mathrm{L}$, sensitive), respectively.

For mature and immature ethanolic extracts in the disc method, maximum size of inhibition zones was 35 and $36 \mathrm{~mm}$ (70 $\mu \mathrm{L}$, sensitive) respectively. In the well method, maximum size of inhibition zones for mature and immature ethanolic extracts were 28 and $15 \mathrm{~mm}$ (110 $\mu \mathrm{L}$, sensitive), respectively (according to Table 1 inhibition zones that are $\geq 15$ and $\geq 28 \mathrm{~mm}$ show sensitivity and inhibition zones that are $\leq 10$ and $\leq 20$ show resistant) (Table 2). The MIC and MFC of methanolic extract of mature $C$. melo fruit were $25 \times 10^{3}$ and $5 \times 10^{4} \mu \mathrm{L} / \mathrm{mL}$, respectively. Also MIC and MFC of methanolic extract of immature C. melo fruit was $25 \times 10^{3} \mu \mathrm{L} / \mathrm{mL}$. Results of MIC and MFC determination of ethanolic extracts of mature C. melo fruit was $25 \times 10^{3} \mu \mathrm{L} / \mathrm{mL}$. MIC and MFC of ethanolic extract of immature $C$. melo fruit were $25 \times 10^{3}$ and 5 $\times 10^{4} \mu \mathrm{L} / \mathrm{mL}$ (Table 3 ).

Hexadecanoic acid compounds were found in all of the extracts of both mature and immature fruits. But in methanolic extract of the mature fruit, 9, 12-octadecadienoic acid with $36.38 \%$ and hexadeconoic acid with $26.46 \%$, in ethanolic extract of the mature fruit, hexa octadecadienoic with $25.62 \%$ and in methanolic extract of immature fruit different compounds of benzene with $64.26 \%$ were found. Hexadeconoic acid with $12.71 \%$ and 9, 12-octadecadienoic acid with $27 \%$, 09\% and n-hexadecanoic acid with $19.27 \%$ were most of the compounds in the ethanolic extract of the immature fruit.

Mean results showed that effect of ethanolic extract was more than methanolic extract. Since amount and distribution of extracts were different, disc and well methods results do not support each other but in total there was a significant relation between inhibition zone diameters with increasing extracts in disc and well methods $\mathrm{P}=0.02$ (Table 4). 
Table 2. Inhibition Zones (mm) Against Different Amounts of C. melo Alcoholic and Aqueous Extracts ( $\mu \mathrm{L})$ by Disc and Well Diffusion Methods

\begin{tabular}{|c|c|c|c|c|c|}
\hline Fruit Type & Methods & Concentration, $\mu \mathrm{L}$ & $\begin{array}{l}\text { Inhibition Zone of } \\
\text { Methanolic Extract }{ }^{\text {a }}\end{array}$ & $\begin{array}{l}\text { Inhibition Zone of } \\
\text { Ethanolic Extract }^{\mathrm{a}}\end{array}$ & $\begin{array}{l}\text { Inhibition Zone of } \\
\text { Aqueous Extract }^{\mathrm{a}}\end{array}$ \\
\hline \multirow{8}{*}{ Mature } & \multirow{4}{*}{ Disc } & 40 & 8 & 26 & 0 \\
\hline & & 50 & 9 & 28 & 0 \\
\hline & & 60 & 11 & 33 & 0 \\
\hline & & 70 & 12 & 35 & 0 \\
\hline & \multirow{4}{*}{ Well } & 80 & 12 & 24 & 0 \\
\hline & & 90 & 13 & 25 & 0 \\
\hline & & 100 & 14 & 26 & 0 \\
\hline & & 110 & 15 & 28 & 0 \\
\hline \multirow{8}{*}{ Immature } & \multirow{4}{*}{ Disc } & 40 & 9 & 30 & 0 \\
\hline & & 50 & 10 & 31 & 0 \\
\hline & & 60 & 11 & 34 & 0 \\
\hline & & 70 & 12 & 36 & 0 \\
\hline & \multirow{4}{*}{ Well } & 80 & 11 & 12 & 0 \\
\hline & & 90 & 13 & 13 & 0 \\
\hline & & 100 & 16 & 14 & 0 \\
\hline & & 110 & 17 & 15 & 0 \\
\hline \multicolumn{6}{|c|}{${ }^{\mathrm{a}}$ Values are expressed as mm. } \\
\hline \multicolumn{6}{|c|}{ Table 3. MIC and MFC Determination of the C. melo Extracts on C. albicans a } \\
\hline \multirow{2}{*}{\multicolumn{2}{|c|}{ Fruit Type }} & \multicolumn{2}{|c|}{ Methanolic Extract } & \multicolumn{2}{|c|}{ Ethanolic Extract } \\
\hline & & MIC & MFC & MIC & MFC \\
\hline Mature & & $25 \times 10^{3}$ & $5 \times 10^{4}$ & $25 \times 10^{3}$ & $25 \times 10^{3}$ \\
\hline Immature & & $25 \times 10^{3}$ & $25 \times 10^{3}$ & $25 \times 10^{3}$ & $5 \times 10^{4}$ \\
\hline
\end{tabular}

a Values are expressed as $\mu \mathrm{g} / \mathrm{mL}$.

Table 4. The Mean and Standard Deviation of Inhibition Zones (mm) Against Different Amounts of C. melo Extracts $(\mu \mathrm{L})$ by Disc and Well Diffusion Methods a

\begin{tabular}{|c|c|c|c|c|}
\hline Methods & Concentration, $\mu \mathbf{L}$ & Extract & Mature & Immature \\
\hline \multirow{8}{*}{ Disc } & \multirow{2}{*}{40} & Methanolic & $8 \pm 1$ & $9 \pm 3$ \\
\hline & & Ethanolic & $26 \pm 3$ & $30 \pm 3$ \\
\hline & \multirow{2}{*}{50} & Methanolic & $9 \pm 2$ & $10 \pm 2$ \\
\hline & & Ethanolic & $28 \pm 2$ & $31 \pm 2$ \\
\hline & \multirow{2}{*}{60} & Methanolic & $11 \pm 1$ & $11 \pm 2$ \\
\hline & & Ethanolic & $33 \pm 2$ & $34 \pm 2$ \\
\hline & \multirow{2}{*}{70} & Methanolic & $12 \pm 2$ & $12 \pm 2$ \\
\hline & & Ethanolic & $35 \pm 3$ & $36 \pm 2$ \\
\hline \multirow{8}{*}{ Well } & \multirow{2}{*}{80} & Methanolic & $12 \pm 1$ & $11 \pm 3$ \\
\hline & & Ethanolic & $24 \pm 3.6$ & $12 \pm 2.66$ \\
\hline & \multirow{2}{*}{90} & Methanolic & $13 \pm 1$ & $13 \pm 2$ \\
\hline & & Ethanolic & $25 \pm 4.36$ & $13 \pm 4.36$ \\
\hline & \multirow{2}{*}{100} & Methanolic & $14 \pm 2.62$ & $16 \pm 1.72$ \\
\hline & & Ethanolic & $26 \pm 4$ & $14 \pm 1$ \\
\hline & \multirow{2}{*}{110} & Methanolic & $15 \pm 3$ & $17 \pm 1$ \\
\hline & & Ethanolic & $28 \pm 2.62$ & $15 \pm 3.61$ \\
\hline
\end{tabular}

\footnotetext{
${ }^{\mathrm{a}}$ Data are presented by mean \pm SD.
} 


\section{Discussion}

In present study, both mature and immature ethanolic and methanolic extracts of $C$. melo fruit showed anti-Candida effects. So these extracts had compounds that were effective against $C$. albicans. However, some extracts had better antifungal effects compared to others.

In recent years, interest in the application of essential oils in the treatment of infectious diseases has notably increased. In this study, we evaluated the anti C. albicans activity of essential oils from 16 medicinal plants in Iran. C. albicans is responsible for the majority of infections in humans. Also medicinal plants are used in different disease treatments and they are popular all over the world [7]. Different studies showed anti-fungal activity of medicinal plants against C. albicans [1]. Nchu et al. in South Africa showed that the leaf extracts of Markhamia obtusifolia had effects against C. albicans in vitro [23]. In Iran, Amini et al. reported that three medicinal plant essential oils of Zataria multiflora, Thymus vulgaris and Thymus kotschyanus are effective against mycelial growth of $P$. aphanidermatum, $R$. solani, F. graminearum [12]. In our study methanolic extract of mature and immature, also ethanolic extract of mature and immature $C$. melo fruit showed anti-fungal effects against C. albicans. Bioactivity of phytochemical constituents of different parts of plants that are used in different studies may be similar, so extracts of different plant parts can have anti-fungal affects against fungal strains [18]. Varalakshmi et al. in India reported that Garcinia indica fruit extract had both anti-fungal (C. albicans, A. niger, Fusarium spp. and Penicillium spp.) and antibacterial properties [20]. Also in our study MIC values confirmed inhibitory effects of $C$. melo fruits on C. albicans. It was verified that both of mature and immature wild melon fruits had anti-fungal effects on C. albicans. In the other hand, based on the ability of different plant compounds to inhibit fungi, results of studies may be different $[20,23,24]$.

In other study Sharma et al. in India showed that ethanolic extracts of Rumex nepalensis and Jacquinia ruscifolia had a broad spectrum of activity against fungal pathogens [25]. Mature and immature ethanolic extracts in the disc method in our research showed that maximum size of inhibition zone was 35 and $36 \mathrm{~mm}$, respectively. In the well method, maximum size of inhibition zone for mature and immature ethanolic extracts was 28 and 15 $\mathrm{mm}$, respectively. But maximum size of inhibition zone for mature and immature methanolic extracts in the disc method was $12 \mathrm{~mm}$ and in well method were 15 and 17 $\mathrm{mm}$, respectively. So ethanolic extract was more effective in compared to mature and immature methanolic extracts. Also by increasing the amount of ethanolic extract of mature and immature wild melon fruit using the disc and well methods, the inhibition zone was increased. So it might be with increasing the amount of extract, diffusion of extract in medium rises and it shows greater antifungal effect [2]. Steenkamp et al. in South Africa showed that crude methanol and water extracts of 32 plant species inhibited C. albicans growth [1]. In Uruguay, Diaz-Dellavalle et al. determined that aqueous extract of 10 plant species exhibit anti-fungal activity against Alternaria spp. [26]. Aqueous extract of both mature and immature fruits of our study had no effect on C. albicans compared to alcoholic extracts, so it may be some plant compounds such as phenols and alcohols have more anti-fungal potency than other types of extract [2].

Kumar and Kamaraj in India using GC/MS demonstrated the chemical composition of Cucumis anguria (such as 9-hexadeconoic acid, n-hexadeconoic acid, hexadeconoic acid, ethyl ester and phytol) and they also proved that ethanolic extract of Cucumis anguria had anti-bacterial and anti-fungal activities [22]. In our study GC/MS results showed that hexadecanoic acid compound, 9, 12-octadecadienoic acid, different compounds of benzene and nhexadecanoic acid were most of the compounds. Indeed, the plant contains many types of polyphenols, ranging from monomers to oligomers which may induce various anti-microbial effects [7]. Different components in plants act as anti-oxidants and by activating $\mathrm{H}_{2} \mathrm{O}_{2}$ they cause oxidative-stress-related responses in mold cells [27].

Pozzatti et al. in Brazil showed the effects of essential oils of rosemary in inhibition of C. albicans and C. dubliniensis. The primary mechanism of antimicrobial activity of essential oils is associated with their lipophilicity and consequent interactions with the microbial cell membrane. These interactions may result in changes and losses in the enzymatic and structural components of fungal cells [24]. For example studies showed that anti-microbial effect is due to chemical reaction of plant compounds with thiol groups of various enzymes [28].

These studies demonstrated that different parts of plants have anti-fungal activity and are worthful for further investigations in order to identify their active compounds and their clinical applications for treatment of mycosis $[2,18]$. According to the widespread activity of natural anti-fungus substances in plants, we hope that results of this study would help to increase the identification and use of medicinal plants.

\section{Acknowledgements}

This thesis (Code: 15930506901010) done by Issa Gholampour-Azizi. This study was supported by Faculty of Medicine and Microbiology Sciences and Research Branch, Islamic Azad University, Babol, Iran.

\section{Authors' Contributions}

Issa Gholampour-Azizi carried out the study, collected data, performed the statistical analysis and prepared the manuscript. Samaneh Rouhi helped in writing the manuscript. Fahimeh Yahyayi supervised the study and participated in designing and conducting the study and also manuscript preparation. All authors have studied and approved the content of the present manuscript. 


\section{Conflict of Interest}

The authors declare no conflict of interest.

\section{Funding/Support}

This paper had been done by personal expenses.

\section{References}

1. Steenkamp V, Fernandes AC, Van Rensburg CEJ. Screening of Venda medicinal plants for antifungal activity against Candida albicans. S Afr J Bot. 2007;73(2):256-8.

2. Naeini A, Khosravi AR, Chitsaz M, Shokri H, Kamlnejad M. AntiCandida albicans activity of some Iranian plants used in traditional medicine. J Mycol Med. 2009;19(3):168-72.

3. Oberoi JK, Wattal C, Goel N, Raveendran R, Datta S, Prasad K Non-albicans Candida species in blood stream infections in a tertiary care hospital at New Delhi, India. Indian J Med Res. 2012;136(6):997-1003.

4. Behzadi P, Behzadi E, Yazdanbod H, Aghapour R, Akbari Cheshmeh M, Salehian Omran D. Urinary tract infections associate with Candida albicans. J clin Med. 2010;5(4):277-9.

5. Parmeland L, Gazon M, Guerin C, Argaud L, Lehot JJ, Bastien O, et al. Candida albicans and non-Candida albicans fungemia in an institutional hospital during a decade. Med Mycol. 2013;51(1):33-7.

6. Yang YL, Hung CC, Wang AH, Tseng FC, Leaw SN, Tseng YT, et al. Oropharyngeal colonization of HIV-infected outpatients in Taiwan by yeast pathogens. J Clin Microbiol. 2010;48(7):2609-12.

7. Casaroto AR, Lara VS. Phytomedicines for Candida-associated denture stomatitis. Fitoterapia. 2010;81(5):323-8.

8. Nunez-Palenius HG, Gomez-Lim M, Ochoa-Alejo N, Grumet R, Lester G, Cantliffe DJ. Melon fruits: genetic diversity, physiology, and biotechnology features. Crit Rev Biotechnol. 2008;28(1):13-55.

9. Nadimi M, Zia M, Madani M. The effect of aqueous and ethanolic extracts of Teucrium polium on Candida albicans and two species of Malassezia. Zahedan J Res Med Sci. 2013;15(8):34-8.

10. Marzouk B, Marzouk Z, Decor R, Edziri H, Haloui E, Fenina N, et al. Antibacterial and anticandidal screening of Tunisian Citrullus colocynthis Schrad. from Medenine. J Ethnopharmacol. 2009;125(2):344-9.

11. Kumar SS, Kamaraj M. Antimicrobial activity of Cucumis anguria L. by agar well diffusion methods. Bot Res Int. 2011;4(2):41-2.

12. Amini M, Safaie N, Salmani MJ, Shams-Bakhsh M. Antifungal activity of three medicinal plant essential oils against some phytopathogenic fungi. Trakia J Sci. 2012;10(1):1-8.

13. Dahham SS, Ali MN, Tabassum H, Khan M. Studies on antibacterial and antifungal activity of pomegranate (Punica granatum L.). Am Eurasian J Agric Environ Sci. 2010;9(3):273-81.

14. Kretschmar M, Hube B, Bertsch T, Sanglard D, Merker R, Schroder $\mathrm{M}$, et al. Germ tubes and proteinase activity contribute to viru- lence of Candida albicans in murine peritonitis. Infect Immun. 1999;67(12):6637-42.

15. Saigal S, Bhargava A, Mehra SK, Dakwala F. Identification of Candida albicans by using different culture medias and its association in potentially malignant and malignant lesions. Contemp Clin Dent. 2011;2(3):188-93.

16. Shariati A, Pordeli HR, Khademiyan A. [ Evaluation of the antibacterial activity of the extracts of date palm (Phoenix dactylifera L.) fruits and pits on multi-resistant Staphylococcus aureus]. Persian. Food Technol Nut. 2010;7(4):42-8.

17. Sharafati-Chaleshtori A, Sharafati-Chaleshtori R, SharafatiChaleshtori F, et al. [Antibacterial effects of ethanolic extract of walnut leaves (Juglans regia) on Propionibacterium acnes]. Persian. J Zanjan Univ Med Sci. 2010;18(71):42-9.

18. Shai LJ, McGaw LJ, Eloff JN. Extracts of the leaves and twigs of the threatened tree Curtisia dentata (Cornaceae) are more active against Candida albicans and other microorganisms than the stem bark extract. S Afr J Bot. 2009;75(2):363-6.

19. Espinel-Ingroff AV, Pfaller MA. Susceptibility test methods; yeasts and filamentous in fungi. In: Murray PR, Baron EJ, Pfaller MA, editors. Manual of clinical microbiology. 9th ed. Washington D.C.: ASM Press; 2007: 1972.

20. Varalakshmi KN, Sangeetha CG, Shabeena AN, Sunitha SR, Vapika J. Antimicrobial and cytotoxic effects of Garcinia indica fruit rind extract. Am Eurasian J Agric Environ Sci. 2010;7:652-6.

21. Baron EJ, Peterson LR, Finegold SM. Methods for testing antimicrobial effectiveness. In: Tille P. Bailey \& Scott's diagnostic microbiology. 13th ed. USA: Mosby; 2013:168-93.

22. Kumar SS, Kamaraj M. Analysis of phytochemical constituents antimicrobial activities of Cucumis anguri L. against clinical pathogene. Am Eurasian J Agric Environ Sci. 2010;7(7-8):176-8.

23. Nchu F, Aderogba MA, Mdee LK, Eloff JN. Isolation of anti-Candida albicans compounds from Markhamia obtusifolia (Baker) Sprague (Bignoniaceae). S Afri J Bot. 2010;76(1):54-7.

24. Pozzatti P, Loreto ES, Nunes Mario DA, Rossato L, Santurio JM, Alves SH. Activities of essential oils in the inhibition of Candida albicans and Candida dubliniensis germ tube formation. J Med Mycol. 2010;20(3):185-9.

25. Sharma RS, Mishra V, Singh R, Seth N, Babu CR. Antifungal activity of some Himalayan medicinal plants and cultivated ornamental species. Fitoterapia. 2008;79(7-8):589-91.

26. Diaz Dellavalle P, Cabrera A, Alem D, Larranaga P, Ferreira F, Dalla Rizza M. Antifungal activity of medicinal plant extracts against phytopathogenic fungus Alternaria spp. Chilean J Agric Res. 2011;71(2):231-9.

27. Maeta K, Nomura W, Takatsume Y, Izawa S, Inoue Y. Green tea polyphenols function as prooxidants to activate oxidative-stressresponsive transcription factors in yeasts. Appl Environ Microbiol. 2007;73(2):572-80.

28. Motsei ML, Lindsey KL, van Staden J, Jäger AK. Screening of traditionally used South African plants for antifungal activity against Candida albicans. J Ethnopharmacol. 2003;86(2-3):235-41. 